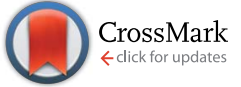

Cite this: RSC Adv., 2017, 7, 1822

Received 5th October 2016

Accepted 13th December 2016

DOI: $10.1039 / c 6 r a 24762 h$

www.rsc.org/advances

\section{Enhanced seed germination and plant growth by atmospheric pressure cold air plasma: combined effect of seed and water treatment}

\begin{abstract}
L. Sivachandiran ${ }^{a b}$ and A. Khacef ${ }^{\star a}$
The combined effect of non-thermal plasma treatment of water and seeds on the rate of germination and plants growth of radish (Raphanus sativus), tomato (Solanum lycopersicum), and sweet pepper (Capsicum annum) have been investigated using dielectric barrier discharges in air under atmospheric pressure and room temperature. A cylindrical double dielectric barrier discharge reactor is used for water activation and a plate-to-plate double DBD reactor is employed for seed treatment. The activation of water, for 15 and $30 \mathrm{~min}$, lead to acidic solutions $(\mathrm{pH} \approx 3)$ with moderate concentrations of nitrate $\left(\mathrm{NO}_{3}{ }^{-}\right)$and hydrogen peroxide $\left(\mathrm{H}_{2} \mathrm{O}_{2}\right)$. Plasma activated water (PAW) has shown a significant impact on germination as well as plant growth for the three types of seeds used. Interestingly, the positive effect, in seed germination and seedling growth, has been observed when the PAW and plasma-treated seeds (10 and $20 \mathrm{~min}$ ) were combined. In one hand, when the seeds were (tomato and pepper) exposed to $10 \mathrm{~min}$ plasma and watered with PAW-15 for first 9 days followed by tap water for 51 days, the stem length is increased about $60 \%$ as compared to control sample. On the second hand, for longer exposures of seeds and water to plasma discharges, a negative effect is observed. For instance, plasma-treated seeds watered with PAW-30, the plant growth and vitality were decreased as compared to control sample. These results revealed that the developed cold plasma reactors could be used to significantly improve the seed germination as well as plant growth, nevertheless, the plasma treatment time has to be optimized for each seeds.
\end{abstract}

\section{Introduction}

As reported by the United Nations Food and Agriculture Organization (FAO), the global food shortages will become three times more likely as a result of climate change, fast development of industrialization and urbanization. Since, the cultivable land is hard to increase, the only way to address the food shortage is to increase the crop yield in an economically viable process. It is widely believed that by increasing the rate of seed germination and plant growth, the world population food needs could be met. The major cause of low germination of seeds of various plant is often connected to the seed surface and soil contamination with bacteria, microorganisms and fungi. The traditional methods used to improve the crop yield are; (i) fertilization, (ii) irrigation, however, both methods have associated disadvantages like economic and environmental problems., ${ }^{\mathbf{1} 2}$

More recently, the innovative non-thermal plasma (NTP) technology has drawn considerable attention in the field

${ }^{a}$ GREMI, UMR 7344, CNRS-Université d'Orléans, 14 rue d'Issoudun, BP 6744, 45067 Orléans Cedex 02, France.E-mail: ahmed.khacef@univ-orleans.fr

${ }^{b}$ SRM Research Institute, Department of Chemistry, SRM University, Kattankulathur, Kancheepuram 603203 (D.t.), India of agriculture and food packaging as an alternative/ complementary for stimulating plant growth and reducing pathogen/chemical contamination of seeds. ${ }^{3-5}$ The NTP is an ionized gas which can be generated in different gas mixtures using microwaves, radio frequency, pulsed or alternative current in various setups such as dielectric barrier discharge (DBD), atmospheric pressure plasma jet (APPJ), and corona discharges. ${ }^{6-8}$ In such plasmas, in one hand, the heavy particles (ions, molecules) remain at low temperature making NTP suitable for the surface treatment of sensitive materials. On the other hand, the electron temperature is high enough to produce a variety of species, especially reactive oxygen and nitrogen species (ROS and RNS), and UV radiation, which in turn acts efficiently in the decontamination and sterilization of surfaces in contact with NTP discharges.,910

Seeds produced by commercial seed companies are commonly treated with insecticides and fungicides in attempt to enhance the survivability of the planted seed. Because a film coating provides a polymer that encapsulates a seed, it reduces the potential health hazards during transportation, storage, and planting. Seed treatments have also been used to enhance germination as in case, for instance, of seeds coated with peroxide compounds that provide oxygen to seeds planted under anoxic soil conditions. ${ }^{11}$ In other instances, delayed 
germination has been investigated to prevent damage of seed sown in a cold wet soil. ${ }^{12}$ Other seed technologies use macro or micronutrients or beneficial bacteria to improve early plant growth. ${ }^{13}$

Regarding the use of plasma technology, recent published works indicate the positive effect of plasma treatment on seed germination, plant development. ${ }^{14-18}$ Volin et al. ${ }^{19}$ achieved either delayed or accelerated germination in several different agricultural species without significantly affecting the percentage of germination. For an example, using a selective gas and plasma conditions, germination was delayed in pea, radish, soybean, corn and bean seed, while the germination was accelerated in soybean and corn seed. In addition, the change in the wettability of the seeds, at least partially due to the oxidation of their surface under plasma treatment, can lead to faster germination and more yield as demonstrated by Jiang et al. ${ }^{14}$ for wheat and oats. Plasma treatment can have a variety of effects on the morphology of seeds due to its complex interaction with organic materials and living cells. Another consequence of the plasma treatment is the modification of surface properties and sterilization of the seeds as reported by Khamsen $e t a l .{ }^{20}$ and Basaran and Akhan. ${ }^{21}$

Besides of their antimicrobial properties, non-thermal plasma-activated water (PAW) can also inactivate a variety of microorganisms ${ }^{22}$ and it could be used as a fertilizer. ${ }^{17}$ It is widely agreed that the bactericidal activity of PAW derives from the combined action of a high positive oxidation reduction potential (ORP) and a low $\mathrm{pH} .{ }^{22}$ Generally, PAW is produced by arc and/or gliding arc discharge on water surface. When plasma discharge is created in contact with water, the water must be treated in a static mode to avoid the electrical accidents. Furthermore, even within 200 seconds of discharge the water $\mathrm{pH}$ is decreased to 5 and the $\mathrm{H}_{2} \mathrm{O}_{2}$ concentration is increased to $2 \mathrm{mg} \mathrm{L}{ }^{-1}{ }^{17,23}$ The low $\mathrm{pH}$ and elevated concentration of $\mathrm{H}_{2} \mathrm{O}_{2}$ notably affect the seed germination and plant growth. ${ }^{24}$ Takahata et al. ${ }^{18}$ investigated the effect of bubble (one tube) discharge in drained water on plant growth as well as edible parts of the plant. Authors reported that the plants watered with plasma treated water have shown faster growth and the fruits contain higher sugar. It can be proposed that, gas bubbling through two glass tubes under plasma discharge atmosphere could increase the RNS and ROS concentration in water. Moreover, a double dielectric barrier discharge could significantly decrease the power consumption at atmospheric pressure.

It is well established that the $\mathrm{NO}_{3}{ }^{-}$is the most important form of nitrogen which is one of the essential nutrients for plant as it is a constituent of amino-acids, proteins, chlorophyll and other metabolites and cellular components. In addition, an optimum amount of $\mathrm{H}_{2} \mathrm{O}_{2}$ could activate proteins/genes related to plant growth. Moreover, PAW is an environmentally friendly and cost-effective disinfectant as compared to traditional chemical sanitizers.

In this study, we investigated the effects of non-thermal plasma on radish (Raphanus sativus), tomato (Solanum lycopersicum), and sweet pepper (Capsicum annum) seeds germination and its subsequent effects on plants growth in combination with PAW irrigation. In particular, the effect of the plasma exposure time on the germination rate, stem and root growth have all been evaluated. Beside the short term germination and stem growth study, a long term evaluation of plant growth was also studied for tomato and pepper. For estimating the physicochemical properties of PAW solutions, the hydrogen peroxide $\left(\mathrm{H}_{2} \mathrm{O}_{2}\right)$, nitrate $\left(\mathrm{NO}_{3}{ }^{-}\right)$and nitrite $\left(\mathrm{NO}_{2}{ }^{-}\right)$concentrations as well as electrical conductivity and $\mathrm{pH}$ value were recorded during the experiments.

\section{Experimental}

\subsection{Non-thermal plasma reactors}

In this study, double dielectric barrier discharge reactors (DBD), in two different configurations, have been used for water and seed treatment: (i) cylindrical double DBD (Cyl-DBD) reactor, and (ii) plate-to-plate double DBD (PtP-DBD) reactor, respectively. The Fig. 1 illustrates the schematic of the reactor setups and the plasma discharges.

The Cyl-DBD reactor was particularly designed for plasma injection of reactive species into water. Two tungsten wire electrodes $(1.5 \mathrm{~mm}$ diameter, $120 \mathrm{~mm}$ length) separated by a space gap of $10 \mathrm{~mm}$ were inserted into glass tubes $(7 \mathrm{~mm}$ outer diameter and $1.5 \mathrm{~mm}$ thickness) to generate the discharge. As shown in Fig. 1, the two glass tubes were fixed in a water treatment vessel using Teflon and synthetic air (Air Liquide) was send through both glass tubes at a flow rate of $1 \mathrm{~L} \mathrm{~min}^{-1}$. In order to avoid arcing between the electrodes and the water surface, the distance between the tip of the electrodes and the surface of the water was fixed at approximately $20 \mathrm{~mm}$. The glass tubes were immersed $30 \mathrm{~mm}$ inside the water to improve the dissolution of the active species produced by the plasma. A volume of $250 \mathrm{~mL}$ deionized water (DW) was activated by plasma for 15 and $30 \mathrm{~min}$ and respectively labeled as PAW-15 and PAW-30. The inserted image of Fig. 1 shows that the discharges occur between the tungsten wires in the inner surfaces of the glass tubes as well as between the glass tubes. The air and active species produced in the glass tubes are passed through the DW by bubbling. It is worth to mention that the active species produced between the glass tubes, probably, will not significantly dissolute into the water.

The PtP-DBD reactor was specifically used for seeds treatment. It consists of two aluminium tape electrodes placed on the outer surface of the glass plates ( $3 \mathrm{~mm}$ thickness). At the center of the bottom plate the seeds compartment $(100 \mathrm{~mm}$ length, $20 \mathrm{~mm}$ width, and $3 \mathrm{~mm}$ height) was made by sandwiching two glass plates. The seeds were distributed uniformly in the compartment. All experiments were performed in air at constant flow rate of $1 \mathrm{~L} \mathrm{~min}{ }^{-1}$.

For both reactors, the plasma discharges were generated using a homemade sub-microsecond high voltage pulsed power supply $(40 \mathrm{kV}, 1 \mathrm{kHz})$. The $\mathrm{HV}$ pulses were delivered by a transformer which is powered by ceramic knob capacitors disposed in a Blumlein-like configuration and switched by a hydrogen thyratron. Details of this homemade HV generator are given in ref. 25. The fast voltage rise time allows achieving significant overshoot of breakdown voltages (kilovolts per 


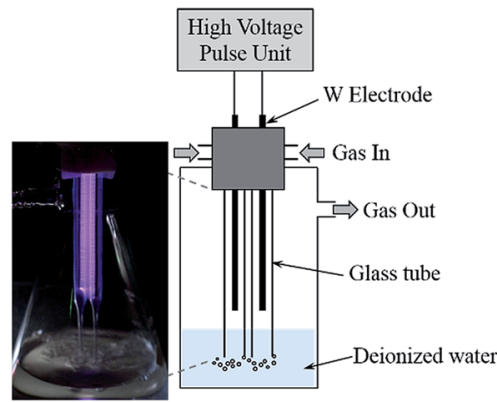

(a)

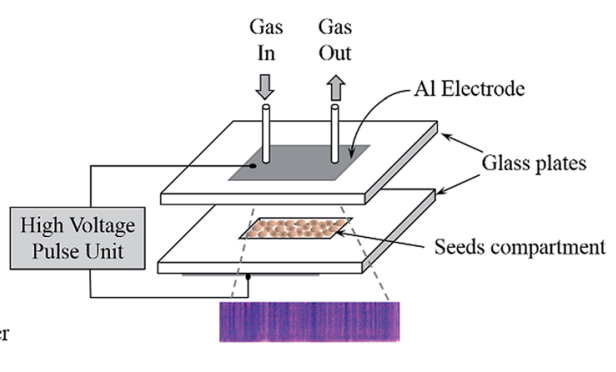

(b)

Fig. 1 Schematic of the plasma reactors for (a) water activation and (b) seeds treatment.

nanosecond) and allows working at larger reduced field values $(\mathrm{E} / \mathrm{n})$ than in ac-conventional DBD.

The voltage and current profiles, during the discharge, were acquired by voltage and current probes (Tektronix P6015A and Pearson 4001, respectively). The output signals were transmitted to a digital oscilloscope (Tektronix DPO 3054) and saved for analysis and energy deposition calculation.

\subsection{Seeds germination and plants growth conditions}

Radish (Raphanus sativus), tomato (Solanum lycopersicum), and sweet pepper (Capsicum annum) were used as a model seed, since these seeds were widely studied in the literature, to investigate the individual and the combined effect of PAW and plasma seed treatment on germination rate and plant growth. Samples of 35 seeds were placed in Petri dishes containing a layer of cotton (each Petri dish contained 5 to 10 seeds). Five replicates ( 35 seeds each) for single treatment were used and all experiments were carried out four times under the same conditions to confirm the reproducibility.

Seed samples were divided into three groups: 10 and $20 \mathrm{~min}$ plasma-treated seeds (P10 and P20) and a control (without any treatment). The samples were watered with $1 \mathrm{~mL}$ of tap water (TW), PAW-15 and PAW-30 at $24 \mathrm{~h}$ interval and placed in a dark chamber at temperature of $(22 \pm 2)^{\circ} \mathrm{C}$ and relative humidity of $(75 \pm 5) \%$.

The number of seed germination was observed and recorded every day. The germination rate, defined as the number of germinated seeds divided by the total number of seeds, was followed during 3 to 6 days depending on the nature of the seeds. Statistical analyses of the data are expressed as the mean \pm standard deviation (SD) of measurements made on five replicate experiments and performed using GNU PSPP software (ver 0.10.4).

For the plant growth studies, control (untreated) and treated seeds were planted in nursery pots containing $30 \mathrm{~g}$ of soil substrate (coco fiber, TRUFFAUT). Every day, $5 \mathrm{~mL}$ of water (TW, PAW-15, and PAW-30) was supplied to the cultivation soil. The plants were cultivated near the window, in an isolated room, and the temperature was controlled at $(22 \pm 2)^{\circ} \mathrm{C}$. After 5 days of cultivation, the stem lengths of the plants were measured and the measurement was continued till 10 days for radish and 20 days for tomato and sweet pepper.

\subsection{Analytical devices}

The gaseous species at the outlet of both plasma reactors were analyzed online and quantified using Fourier transform infrared spectroscopy (FTIR, Nicolet 6700, Thermo Scientific). The ozone concentration was monitored using an ozone analyzer (Ozomat MP, ANSEROS) based on non-dispersive ultra-violet absorption (Lambert-Beer) at a wavelength of $254 \mathrm{~nm}$.

For FTIR measurements, a $10 \mathrm{~m}$ length path cell coupled with liquid nitrogen cooled Mercury-Cadmium-Tellurium (MCT) detector was used. The spectra were collected using Omnic software with 5 scans per spectrum and a spectral resolution of $0.5 \mathrm{~cm}^{-1}$. The background spectrum was collected under air with 16 scans per spectrum. The TQ-analyst software was used for calibration as well as for data processing. The calibration concentrations were adjusted between $500 \mathrm{ppb}$ and $750 \mathrm{ppm}$. A special attention has been paid to select the vibrational and rotational bands for $\mathrm{NO}, \mathrm{NO}_{2}, \mathrm{~N}_{2} \mathrm{O}$ and ozone to avoid the bands overlapping as reported by Sivachandiran et $a .^{26}$

The $\mathrm{pH}$ and electrical conductivity measurements of TW, DW, and PAW were performed using a multi-parameters probe HI99130 (HANNA instruments). The detection and quantification of nitrate $\left(\mathrm{NO}_{3}{ }^{-}\right)$, nitrite $\left(\mathrm{NO}_{2}{ }^{-}\right)$, and hydrogen peroxide $\left(\mathrm{H}_{2} \mathrm{O}_{2}\right)$ in untreated and PAW have been performed by photometric analysis using a digital absorption spectrophotometer (PONSEL Measure, Aqualabo) equipped with light-emitting diodes (wavelengths 400, 468, 518, 591, and $639 \mathrm{~nm}$ ) and $\mathrm{Si}$ detector.

\section{Results and discussion}

\subsection{Plasma discharge characteristics}

The discharge observed between the wires and the inner surfaces of the glass tubes (Cyl-DBD) is filamentary consist of multitude of plasma filaments randomly distributed in the volume. However, in the volume between the glass tubes, the discharge seems to be a pseudo-homogeneous. The typical waveforms of the voltage and current measured for the Cyl-DBD reactor, the minimum voltage to obtain a uniform discharge between the glass tubes, are shown in Fig. 2(a). The pulse width and the amplitude of the applied voltage are $120 \mathrm{~ns}$ and $21 \mathrm{kV}$, respectively. The peak value of the discharge current is $2.4 \mathrm{~A}$. It 

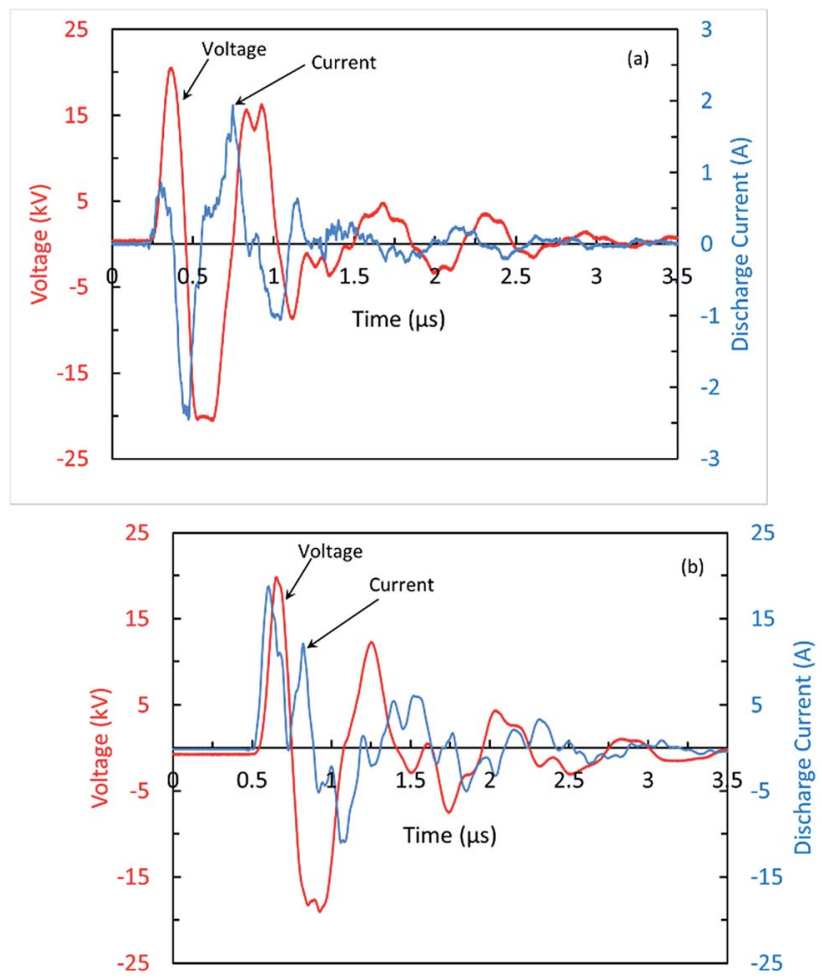

Fig. 2 Typical voltage and current waveforms for (a) Cyl-d-DBD and (b) PtP-d-DBD reactors.

is worth to mention that the discharge current and applied voltage oscillate owing to the RLC oscillation and the reflection due to the impedance mismatch. Similar voltage-current behavior was observed for the PtP-DBD reactor but with a higher current amplitude, up to $18 \mathrm{~A}$, as shown in Fig. 2(b). The higher discharge current measured for DBD plate-to-plate reactor can be correlated to the total discharge area. Sivachandiran et al. ${ }^{25}$ demonstrated that, at a constant applied voltage and frequency, the discharge current increases with increasing the discharge area. The energy deposited in the plasma volume per current pulse is calculated by integrating, over the duration of the discharge, the electric power obtained from the voltage and current signals. Under the present working conditions (at $21 \mathrm{kV}$ and $400 \mathrm{~Hz}$ ), a maximum energy of 7 and $57 \mathrm{~mJ}$ were dissipated into the plasma in each pulse of high voltage for the Cyl-DBD reactor and the PtP-DBD reactor, respectively. These correspond to the electrical energy transferred to sample per second less than 3 and $22 \mathrm{~J} \mathrm{~s}^{-1}$ for both reactors, respectively. It is noteworthy to mention that, in this study authors have not attempted to optimize the plasma operating conditions neither in water activation and nor in seed treatment processes.

\subsection{Plasma activated water (PAW)}

3.2.1. Gas phase characterization. Many reactive species are produced during the plasma discharge in the air. In the gas phase, depending on the injected energy, nitrogen and oxygen molecules are dissociated by the energetic electrons in the discharge mostly leading to the formation of radicals ( $\mathrm{O}$ and
$\mathrm{OH})$, ozone $\left(\mathrm{O}_{3}\right)$, nitrogen oxides $\left(\mathrm{NO}, \mathrm{NO}_{2}\right)$, and excited $\mathrm{N}_{2}$ through several reaction pathways. ${ }^{25}$ Fig. 3 shows a typical FTIR spectrum recorded during DW activation using Cyl-DBD reactor with $2.8 \mathrm{~W}$ plasma input power. Only stable molecules like $\mathrm{O}_{3}$, nitrous oxide $\left(\mathrm{N}_{2} \mathrm{O}\right)$, and carbon dioxide $\left(\mathrm{CO}_{2}\right)$ were measured at the reactor outlet. Interestingly, even after $30 \mathrm{~min}$ of plasma treatment, the measured $\mathrm{N}_{2} \mathrm{O}$ and $\mathrm{O}_{3}$ concentration remain constant at $(30 \pm 2)$ and $(850 \pm 10) \mathrm{ppm}$, respectively. The gas phase characterization, without water in the flask, has also been performed and similar kind of species have been quantified. It is noteworthy to mention that the $\mathrm{CO}_{2}$ peak appears from the background. Importantly, neither nitrogen oxide (NO) and nor nitrogen dioxide $\left(\mathrm{NO}_{2}\right)$ were detected in the gas phase in that conditions. The absence of $\mathrm{NO}_{X}$ in the analyzed gas phase, with and without water in the flask, can be correlated to the following facts: (i) probably $\mathrm{NO}_{X}$ are produced lower than the FTIR detection limits $(<0.5 \mathrm{ppm})$, (ii) after bubbling the gas through water these long-lived species could be participated in chemical reactions at the gas-liquid interface, where the dissolved NO and $\mathrm{NO}_{2}$ react irreversibly with $\mathrm{H}_{2} \mathrm{O}$ to produce nitrous $\left(\mathrm{HNO}_{2}\right)$ and nitric $\left(\mathrm{HNO}_{3}\right)$ acids. In one hand, the reactions of these molecules from the gas phase with the water could result in acidification and generation of $\mathrm{NO}_{3}{ }^{-}, \mathrm{NO}_{2}{ }^{-}$and $\mathrm{H}_{2} \mathrm{O}_{2}$ species. On the other hand, $\mathrm{NO}_{3}{ }^{-}, \mathrm{NO}_{2}{ }^{-}$and $\mathrm{H}_{2} \mathrm{O}_{2}$ could serve as a starting reactive species to generate $\mathrm{NO}, \mathrm{NO}_{2}$, hydroxyl radicals $(\mathrm{OH})$, and $\mathrm{HNO}_{3}$ in liquid.

3.2.2. Evaluation of physicochemical properties of PAW. It can be suggested that the generation of plasma in gas-phase and bubbling through liquid might be an effective way to produce optimum concentrations of RNS and ROS. Lackmann et $a{ }^{27}{ }^{27}$ suggested that the active species not only produced in the gas phase by plasma discharge, but through photolysis by plasma emitted UV and VUV photons in the liquid phase. In order to understand the plasma-induced acidification of DW, the nitrate $\left(\mathrm{NO}_{3}{ }^{-}\right)$and nitrite $\left(\mathrm{NO}_{2}{ }^{-}\right)$ions as well as hydrogen peroxide $\left(\mathrm{H}_{2} \mathrm{O}_{2}\right)$ concentration in untreated water and PAW were measured using spectrophotometric methods and the results are reported in Table 1 . All measurements were performed immediately after the plasma treatment.

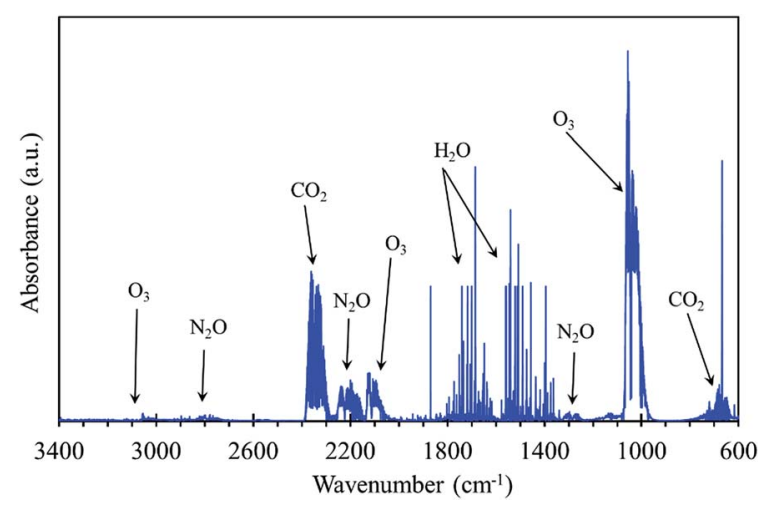

Fig. 3 Typical gas phase FTIR spectrum acquired during DW treatment using Cyl-DBD reactor at room temperature and atmospheric pressure: $1 \mathrm{~L} \mathrm{~min}{ }^{-1}$ air, $20.5 \mathrm{kV}$ and $400 \mathrm{~Hz}$. 
Table 1 Physicochemical properties of TW, DW, and PAW for 15 and 30 min plasma activation time

\begin{tabular}{llcll}
\hline Water & $\mathrm{pH}$ & Electrical conductivity $\left(\mu \mathrm{S} \mathrm{cm}^{-1}\right)$ & $\mathrm{NO}_{2}^{-}\left(\mathrm{mg} \mathrm{L}^{-1}\right)$ & $\mathrm{NO}_{3}^{-}\left(\mathrm{mg} \mathrm{L}^{-1}\right)$ \\
\hline TW & $7.19 \pm 0.01$ & $336 \pm 6$ & 0.1 & $4.90 \pm 0.10$ \\
DW & $6.82 \pm 0.01$ & $3.0 \pm 0.1$ & 0 & 0 \\
PAW-15 & $3.65 \pm 0.01$ & $32 \pm 1$ & 0 & $8.90 \pm 0.10$ \\
PAW-30 & $3.15 \pm 0.01$ & $75 \pm 2$ & 0 & $16.22 \pm 0.10$
\end{tabular}

As can be noticed in Table 1 , the $\mathrm{NO}_{3}{ }^{-}$concentration in 250 $\mathrm{mL}$ water, linearly increases with increasing the plasma treatment time. The nitrate concentration increased from 0 to $8.9 \mathrm{mg} \mathrm{\textrm {L } ^ { - 1 }}$ in the first $15 \mathrm{~min}$ and then to $16.22 \mathrm{mg} \mathrm{L}^{-1}$ for 30 min plasma treatment, which is 1.8 times more than the amount produced after 15 min of plasma treatment. Moreover, surprisingly, no significant amount of $\mathrm{NO}_{2}{ }^{-}$is produced even after 30 min plasma treatment. This absence of $\mathrm{NO}_{2}{ }^{-}$as compared to $\mathrm{NO}_{3}{ }^{-}$can be explained by the fact that the transformation of $\mathrm{NO}_{2}{ }^{-}$into $\mathrm{NO}_{3}{ }^{-}$is accelerated at acidic conditions as demonstrated by Oehmigen et al. ${ }^{22}$ For tap water, about 0.1 and $4.9 \mathrm{mg} \mathrm{\textrm {L } ^ { - 1 }}$ of $\mathrm{NO}_{2}^{-}$and $\mathrm{NO}_{3}{ }^{-}$ions were respectively measured.

As shown in Table 1, the pH of the DW dropped quickly to 3.65 during the first $15 \mathrm{~min}$ of plasma activation and reached 3.15 after $30 \mathrm{~min}$ of plasma activation. The increase in conductivity and decrease in $\mathrm{pH}$ are the clear evidence of accumulation of active ions in PAW. The formation of acids and their effects on various reactions have been reported in many studies for example the aqueous solutions were exposed to the pulsed corona, DBD, or gliding arc discharges. ${ }^{22,28,29}$ For discharges generated in gas-liquid environment, the decrease in $\mathrm{pH}$ was mainly attributed to the formation of $\mathrm{HNO}_{2}$ and $\mathrm{HNO}_{3}$ acids. It can be proposed that even though the $\mathrm{HNO}_{2}$ and $\mathrm{HNO}_{3}$ acids are quantified, a complete analysis is needed to establish the relation between the decrease in $\mathrm{pH}$ and the amount of acid produced. This can be demonstrated by comparing the measured molar concentrations of $\mathrm{NO}_{3}{ }^{-}$and $\mathrm{H}^{+}$ ions calculated from the $\mathrm{pH}$ measurements. After 15 and $30 \mathrm{~min}$ of plasma treatment of $250 \mathrm{~mL}$ of DW (PAW-15 and PAW-30), the $\mathrm{pH}$ of 3.65 and 3.15 was measured (see Table 1), respectively. These correspond to molar $\mathrm{H}^{+}$concentrations of $0.22 \times$ $10^{-3}$ and $0.71 \times 10^{-3} \mathrm{~mol} \mathrm{~L}^{-1}$, respectively. It can be suggested that if the acidification by plasma is mainly due to the $\mathrm{HNO}_{3}$ production, the $\mathrm{H}^{+}$and $\mathrm{NO}_{3}{ }^{-}$concentrations should be identical for the same experimental conditions. This is not the case, as reported in Table 1 , the measured $\mathrm{NO}_{3}{ }^{-}$concentrations for PAW-15 and PAW-30 are 8.90 and $16.22 \mathrm{mg} \mathrm{L}^{-1}$, respectively. These values correspond to 0.14 and $0.26 \mathrm{~mol} \mathrm{~L}^{-1}$, respectively. This shows that in addition to the excited nitrogen species and their products $\left(\mathrm{NO}_{2}{ }^{-}, \mathrm{NO}_{3}{ }^{-}\right)$, singlet oxygen could mainly be contributed to the acidification of the solution as demonstrated by Brisset et al. ${ }^{30}$ in corona discharge in air above the surface of an aqueous solution.

The electrical conductivity of PAW increases with increasing the plasma activation time. The conductivity increased to 32 and $75 \mu \mathrm{S} \mathrm{cm} \mathrm{cm}^{-1}$ after 15 and $30 \mathrm{~min}$ plasma activation, respectively, as compared to $3 \mu \mathrm{S} \mathrm{cm}^{-1}$ in the control sample (DW). Additionally, a clear $\mathrm{H}_{2} \mathrm{O}_{2}$ production observed in water during plasma treatment. Since, both glass tubes are immersed in water, one can expect $\mathrm{OH}$ radical formation and subsequent $\mathrm{H}_{2} \mathrm{O}_{2}$ production inside the discharge tube and further dissolution into water. As reported in Table 1, the $\mathrm{H}_{2} \mathrm{O}_{2}$ concentration is almost constant even after 30 min plasma treatment and it is approximately equal to the amount present in TW $(0.12 \mathrm{mg}$ $\mathrm{L}^{-1}$ ). The analysis of PAW revealed that, in one hand the ignition of plasma in the gas phase and the subsequent dissolution of gaseous species into water produces an optimum concentration of RNS, in the second hand it does not produced significant amount of $\mathrm{H}_{2} \mathrm{O}_{2}$. Therefore, it can be concluded that in these plasma conditions, the Cyl-DBD reactor can be used to selectively produce $\mathrm{NO}_{3}{ }^{-}$specie in water.

\subsection{Effect of PAW on seeds germination}

In this section the effect of PAW, especially the role of $\mathrm{NO}_{3}{ }^{-}$ species, on the germination of radish seeds has been examined every $24 \mathrm{~h}$ for 3 days. The seeds are considered to be germinated
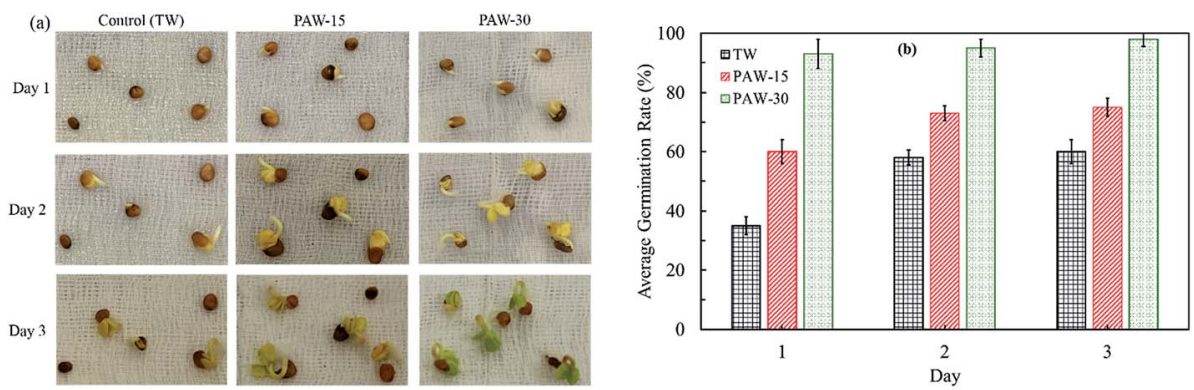

Fig. 4 (a) Seedling growth and (b) average germination rate of radish seeds watered with TW and PAW during the first 3 days after sowing on cotton. 
when radicle emergence was approximately $2 \mathrm{~mm}$. Fig. 4 shows the overall results for radish seeds watered with TW, PAW-15, and PAW-30 during the first 3 days after sowing on wet cotton.

As compared to TW, the plasma-activated water has enhanced the seeds germination rate and the seedling growth. As can be seen in Fig. 4(b), one day after sowing, seeds germination is about $40 \%$ when TW was used, whereas, $60 \%$ and $100 \%$ germination rate have been reached when PAW-15 and PAW-30 are respectively used. In addition, even after 3 days, only $60 \%$ germination is reached with TW. The PAW is not only increased the rate of germination but also improved the seedling growth. The results demonstrate that (Fig. 4(a)), after 3 days, radish seeds watered with PAW-30 have shown average seedling length of about 15 $\mathrm{mm}$, and watered with PAW-15 have shown average seedling length of $5 \mathrm{~mm}$. Therefore, it can be suggested that the plasma water treatment time or the amount of $\mathrm{NO}_{3}{ }^{-}$species is increased the rate of germination and the seedling growth.

It is demonstrated that the reactive oxygen and nitrogen species (RONS) are the main signaling molecules regulating many developmental processes in mammalian, fungi, and plants. The required quantity of reactive species in plants can play an important role on the regulation of growth and development. ${ }^{31}$ Recently, Arc et al. ${ }^{32}$ reviewed the role of nitric oxide (NO) in the seed germination and plant growth, and correlated the role of NO and ROS species on the positive effect of abscisic acid (ABA) production, which is the pivotal hormone responsible for ignition and maintenance of the seed dormancy. It is well established that the $\mathrm{NO}_{3}{ }^{-}$is considered as a major nitrogen source for most plant species. In plants metabolism, the $\mathrm{NO}_{3}{ }^{-}$ reduction into $\mathrm{NO}_{2}{ }^{-}$is catalyzed by nitrate reductase (NR) that produces nitrogen-containing metabolites, such as amino acids and NO. ${ }^{33}$ In particular, $\mathrm{NO}_{3}{ }^{-}$has been shown to promote seed dormancy release and subsequent germination in numerous plant species. ${ }^{34,35}$ Therefore, it can be concluded that the $\mathrm{NO}_{3}{ }^{-}$ species produced by DBD in air and bubbling through water have significantly enhanced the rate of germination.

\subsection{Plasma treatment of seeds}

As reported in Section 2.1., the seeds treatment (dry and wet) is performed using a plate-to-plate DBD reactor, in air at a constant applied voltage of $21 \mathrm{kV}$ and $200 \mathrm{~Hz}$ frequency, and the corresponding pulse energy is $57 \mathrm{~mJ}$. Moreover, no attempt is made to study the influence of plasma injected energy on seed germination. By considering the efficiency of the power supply and the dimensions of the seeds compartment, the corresponding determined power density in the plasma discharge volume is about $130 \mathrm{~W} \mathrm{~cm} \mathrm{c}^{-3}$ for $10 \mathrm{~min}$ treatment. In this preliminary study, the plasma treatment time $(10 \mathrm{~min})$ has been fixed as constant. The effect of plasma treatment time on the rate of germination has been systematically investigated and it will be communicated in the upcoming articles. The FTIR gas phase analysis (results are not shown) shows that only $\mathrm{O}_{3}, \mathrm{~N}_{2} \mathrm{O}$ and $\mathrm{CO}_{2}$ are the species observed downstream the reactor. After $30 \mathrm{~min}$ plasma discharge, without or with seeds in the compartment, the concentrations of $\mathrm{O}_{3}(1600 \mathrm{ppm})$ and $\mathrm{N}_{2} \mathrm{O}(18 \mathrm{ppm})$ remain constant, suggesting that the consumption of these species by the seeds during the process is negligible. Indeed, much work is needed regarding plasma operating conditions on the effect of seed germination and seedling growth.

\subsection{Influence of PAW on plasma treated dry radish seeds germination}

The effect between the PAW and plasma treated seeds on the rate of germination and seedling growth has been investigated. The control and 10 min plasma-treated seeds are concurrently watered with TW and PAW (15 and $30 \mathrm{~min}$ ). Fig. 5 shows the photograph of radish seeds taken on $3^{\text {rd }}$ day of germination for untreated (first row) and 10 min plasma-treated seeds (second row). Similarly to the untreated seeds as reported in Fig. 4(b), the plasma water activation time or $\mathrm{NO}_{3}{ }^{-}$concentration in the water, has significantly improved the germination. Indeed, the viability of the radish seeds does not affected by the plasma
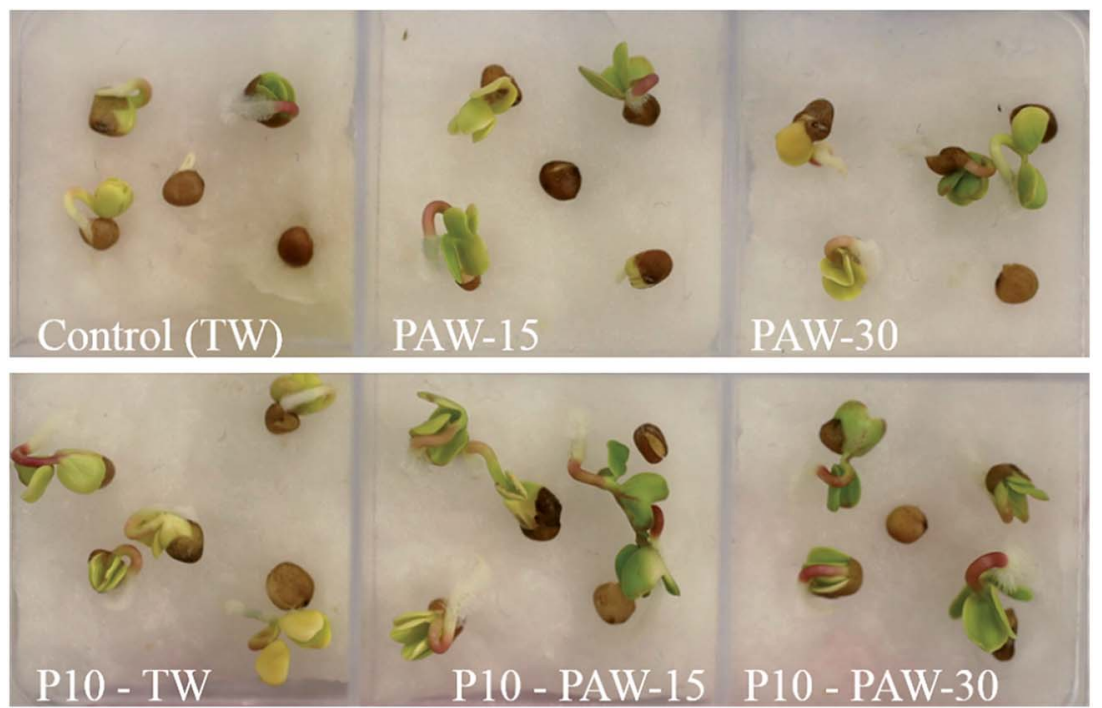

Fig. 5 Photographs of radish germination and seedling growth, after 3 days of sowing, for untreated (first row) and 10 min plasma-treated dry seeds (second row) watered with TW and PAW. 
treatment. Moreover, irrespectively of the water used, $10 \mathrm{~min}$ plasma treated seeds have reached $100 \%$ germination, whereas only $90 \%$ germination is obtained for the untreated-control seeds watered with PAW-15. In addition, the combination of plasma seeds treatment and PAW has significantly improved the germination as compared to the untreated seeds under the similar experimental conditions.

The combined interaction between plasma treated seeds and the plasma-activated water is not yet clearly identified. However, it can be suggested that the plasma discharges directly affect the seed coating and could indirectly influence the cells inside the seed. The seeds immersed into air plasma is subjected to reactions with electrons, ions, reactive species, and UV light emitted by the discharge. This hypothesis supports that the plasma treatment induces changes on the seed surface ${ }^{36}$ and allows radicals to penetrate into the seed and affect the metabolic process of plant growth as shown by Sera et $a l .{ }^{15}$ for wheat and oat treatment. Moreover, the quality of water may play a major role on improving the plants development by providing chemical species. ${ }^{17,37}$

As shown in Fig. 5, the significant positive effect is observed between the plasma-treated seeds and the PAW regarding the rate of germination and the seedling growth. As an example, 10 min plasma treated radish seeds and watered with PAW-15 (P10 - PAW-15) has shown better average seedling growth as compared to untreated seeds and 10 min plasma-treated seeds watered with TW. Notably, 10 min plasma treated seeds watered with PAW-30 (P10 - PAW-30) has reached 100\% germination, nevertheless, the measured average seedling length is shorter than the P10 - PAW-15 sample. As reported in Fig. 4(a), the nontreated seeds watered with PAW-30 have shown longer seedling growth as compared to TW. These findings show that, despite the fact that plasma discharges, on the seed surface, stimulate the germination and seedling growth, the prolonged plasma treatment time significantly affects the seedling growth.
Numerous studies have found that the NTP discharge significantly increased the rate of seed germination., ${ }^{3,4,37,38}$ The improved germination by plasma discharge on the seed surface can be correlated to several factors such as increase in surface wettability, ${ }^{\mathbf{1 4}}$ killing of bacteria and pathogens on the seed surface. ${ }^{\mathbf{2 0 , 2 1}}$ In addition, the local heating probably opens up the seed coating and increases the water intake. The plasma discharge produced RONS such as $\mathrm{O}_{3}, \mathrm{~N}_{2} \mathrm{O}$ and electrons have modified the water uptake rate and increased the germination metabolisms. In contrast, Volin et al. ${ }^{19}$ reported negative effect of plasma treatment on radish seeds with $\mathrm{CF}_{4}$ as a carrier gas at low pressure. After one day, with $5 \mathrm{~min}$ of plasma treatment using rotating plasma reactor, the germination had been delayed about $27 \%$ as compared to non-treated seeds. Authors suggested that the plasma treatment under $\mathrm{CF}_{4}$ atmosphere leads to a thin coating of hydrophobic layer on the seed surface, which decreases the water uptake and subsequently delays the germination rate. In literature, Ji et al. ${ }^{39}$ investigated the effect of carrier gas, i.e. nitrogen $\left(\mathrm{N}_{2}\right)$, argon ( $\left.\mathrm{Ar}\right)$, and air, using a micro-DBD reactor, on coriander seeds (Coriandrum sativum L.) germination and reported that the seed treatment under pure $\mathrm{N}_{2}$ has shown better germination than the air or $\mathrm{Ar}$ atmosphere. Moreover, authors suggested that the nitrogen excited states $\mathrm{N}_{2}\left(\mathrm{~B}^{3} \Pi_{\mathrm{g}}\right)$ produced by discharge play a vital role in seed germination. In addition to that species, electrons, reactive oxygen species, and ions might also have significantly contributed to improve the germination and seedling growth.

\subsection{Combined effect of plasma-treated wet radish seeds and PAW on germination}

The previous results show that the plasma treatment on dry seeds has increased the percentage of germination and seedling growth. However, the effect of plasma discharge on wet seed surface is scarcely studied. It can be proposed that the water
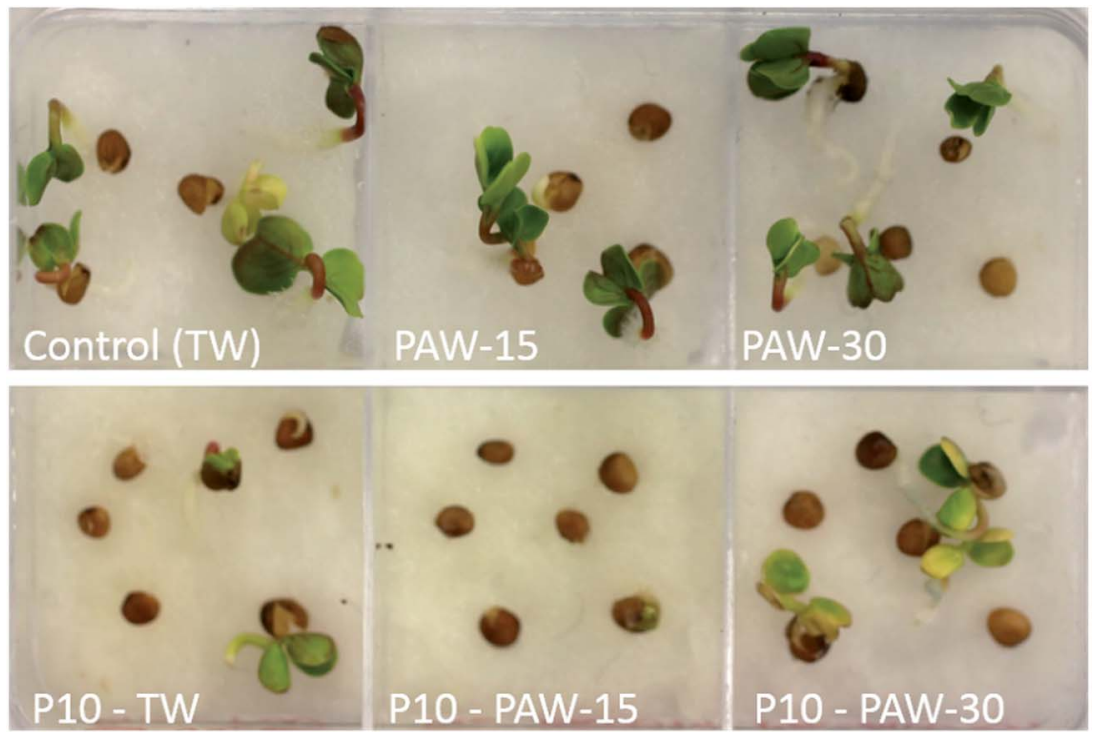

Fig. 6 Photographs of radish germination and seedling growth after $3^{\text {rd }}$ day of sowing for untreated (first row) and 10 min plasma-treated wet seeds (second row) watered with TW and PAW. 
molecules adsorbed on the seed skin could react with the plasma discharge produced active species and, thus, the germination and seedling growth could be significantly affected. Therefore, to evidence this hypothesis, radish seeds are incubated for $15 \mathrm{~h}$ at $22^{\circ} \mathrm{C}$ under dark in cotton soaked with DW then treated by DBD discharge similarly to dry seeds treatment as reported in the previous section. Fig. 6 shows the effect of combination of plasma discharge on wet radish seeds and PAW on germination and seedling growth on $3^{\text {rd }}$ day after sowing. The first row shows the untreated seeds watered with TW, PAW-15 and PAW-30. The second row exhibits the $10 \mathrm{~min}$ plasma treated (labeled as P10) seeds watered with TW, PAW-15 and PAW-30.

As can be seen in Fig. 6, on the untreated wet seeds, as compared to control (TW), neither PAW-15 and nor PAW-30 have shown any significant influence on the rate of germination. However, on dry seeds (Fig. 4(b)) the PAW has shown positive effect and $100 \%$ germination is obtained after $3^{\text {rd }}$ day. This result implies the fact that the water absorbed by the seeds during first hours of imbibition probably controls the germination and induces the rapid metabolic reactions. Surprisingly, the plasma treatment on incubated seeds has shown negative effect regarding germination and the seedling growth. After 10 min plasma treatment (P10) under dry air, only $33 \%$ of germination is reached with TW, which is around $50 \%$ less than the untreated seeds. This result shows that the plasma discharge on wet seed surface modifies the seed surface phenomenon and affects the germination process which is already started after $15 \mathrm{~h}$ incubation in cotton soaked with deionized water. This negative effect of plasma treatment on wet seeds is more pronounced when watered with PAW. The seeds watered with PAW-15 have not germinated even after three days. Moreover, watered with PAW-30 about 50\% germination is reached, indeed their leaves do not seem to be healthy. This phenomenon can be attributed to both plasma discharge effect on the pre-germinated seeds and the PAW quality, i.e. acidity and the $\mathrm{NO}_{3}{ }^{-}$concentration, which could affect the radical protrusion and seedling growth.

\subsection{Seedling growth: shoot and root length}

The positive effect is observed between PAW and the plasma treated radish seeds on the short term germination and seedling growth. Therefore, in order to understand the long term combined effect of PAW and plasma treated radish seeds, the stem and root lengths of radish seeds were measured after 9 days of sowing. The radish seeds were planted in soil substrate and the seedling growth was monitored during days. Fig. 7 shows the effects of plasma treatment (PAW and seeds) on radish cultivation and plant stem length.

In all cases, the plant stem length increases gradually with increasing the cultivation duration. For the untreated radish seeds, data show that the stem length increased when watered with PAW (15 and $30 \mathrm{~min}$ ) as compared to control sample (tap water). On the $5^{\text {th }}$ day of cultivation, the average stem lengths are $4.6 \mathrm{~cm}$ and $5.2 \mathrm{~cm}$ for PAW-15 and PAW-30 respectively, which represent an improvement of about $28 \%$ and $45 \%$ as compared to control sample.

As can be seen in Fig. 7(b), the seeds treated by plasma, prior to cultivation, the best results were obtained for TW and PAW15. For instance, for the seeds watered with TW, the average stem lengths are about 5 and $4.2 \mathrm{~cm}$ for plasma exposure time of 10 and $20 \mathrm{~min}$, respectively. These values are respectively $39 \%$ and $17 \%$ more than the untreated seeds. The plasma discharge effect is clearly demonstrated on the radish seedling growth. However, negative effect is observed for seeds treated by plasma for 10 and 20 min (P10 and P20) and watered with PAW30. The measured stem lengths of P10-PAW-30 is shorter about 36,48 , and $48 \%$, respectively on $5^{\text {th }}, 7^{\text {th }}$, and $9^{\text {th }}$ day as compared to control. This negative effect can be correlated to the acidity of the PAW-30 ( $\mathrm{pH} \approx 3)$.

Fig. 8 shows the image of seedlings harvested after 9 days of sowing for control and plasma-treated samples (seeds and water). The longer root length with more branches was observed for the seeds watered with PAW as compared to control sample. The longest stems and roots were observed for P10 - PAW-15 sample, furthermore, the stem and the leaves were healthier than any other sample. Therefore, it can be concluded that, the plasma treatment of water and radish seeds not only shown a short term effect on the rate of germination but also exhibited a long term effect on stem and root growths. Indeed, it can be suggested that in order to transfer this technology to the industrial level much work is needed. For example, the plasma water treatment and seed treatment have to be studied for various seeds.

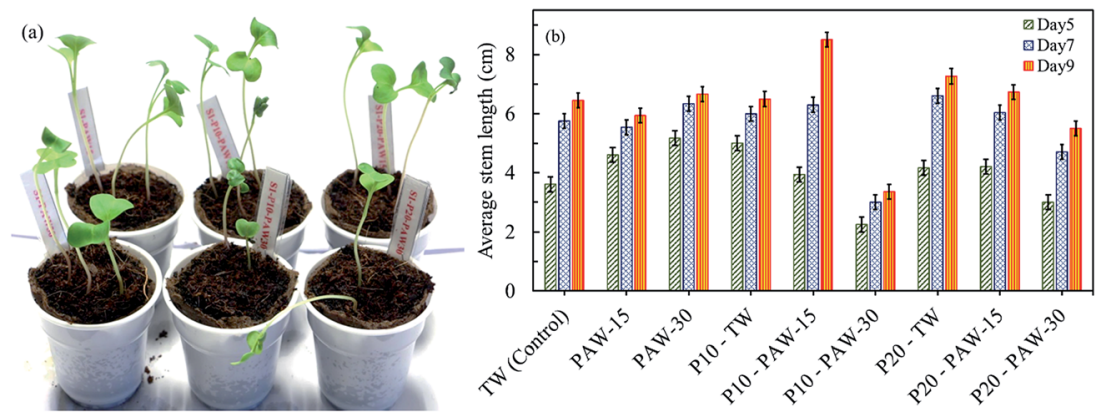

Fig. 7 Combined effect of PAW and plasma seed treatment on radish cultivation: (a) sample of plant growth on day 6 and (b) average stem length on day 5,7 and 9 . 


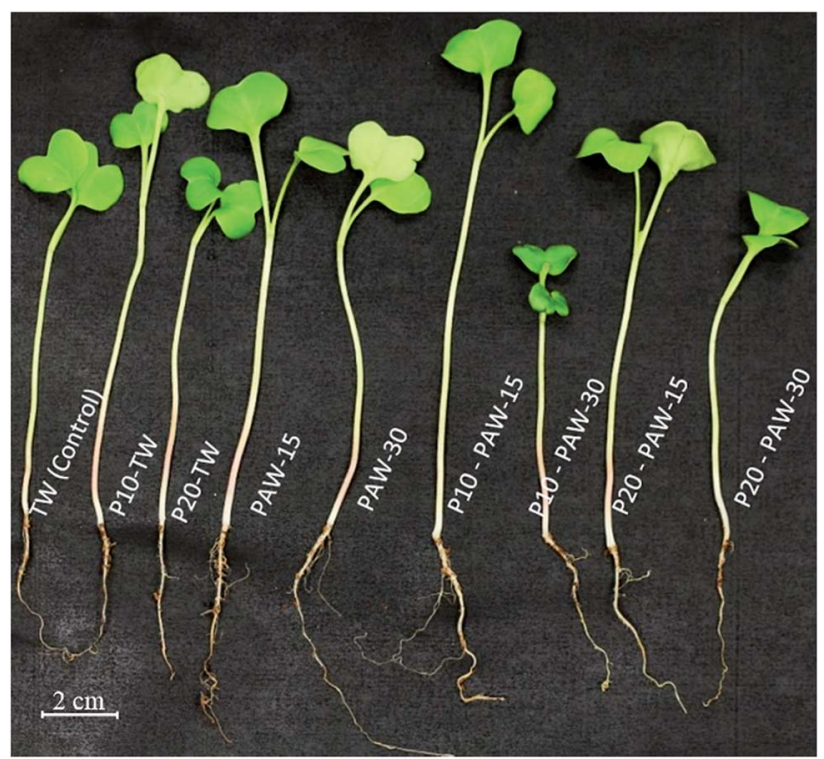

Fig. 8 Image of radish seedlings harvested on $9^{\text {th }}$ day after sowing.

In order to support the hypothesis raised in the previous section, the combined effect of PAW and plasma treated seeds on the germination and stem growth of tomato seeds have also been studied under the similar conditions as radish seeds. Fig. 9 shows the effects of plasma treatment (seeds and water) on tomato plant growth, and the stem length for different experimental conditions. The cultivation of tomato, shows quiet different results as compared to those obtained for radish as shown in Fig. 7.

It was found that, except on $5^{\text {th }}$ day, the plasma treated (P10 and P20) and non-treated (control) tomato plants grow faster when watered with TW. Notably, when PAW is used, the seedling growth is slowed down as compared to the control sample. In contrary to the results obtained with radish, the tomato stem growth shows a similar behavior irrespectively of the plasma water activation time.

As reported in Fig. 8, the better stem and root lengths were measured for the untreated seeds watered with PAW-30, and 10 min plasma treated seeds watered with PAW-30 (P10 - PAW30). Thus, in order to study the long term effect of plasma treatment, the control (TW), PAW-30 and P10 - PAW-30 samples were grown for 60 days. Fig. 10 shows the photographs of tomato and pepper plants growth after 60 days of sowing and all the pots were cultivated under similar conditions. It is worth to mention that the control sample is watered with tap water for all 60 days, whereas, the other samples were watered with PAW-30 for the first 9 days, and then watered with TW during 51 days.

As can be seen in Fig. 10, the results clearly show positive effect of the plasma treatment, seed and water, on tomato and
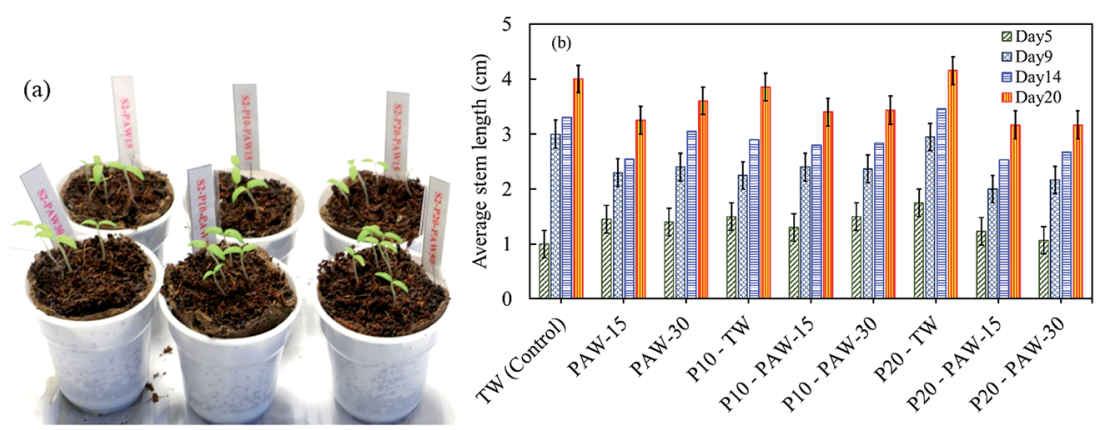

Fig. 9 Combined effect of PAW and plasma seed treatment on tomato cultivation: (a) sample of plant growth on day 6 and (b) average stem length on day $5,9,14$ and 20.
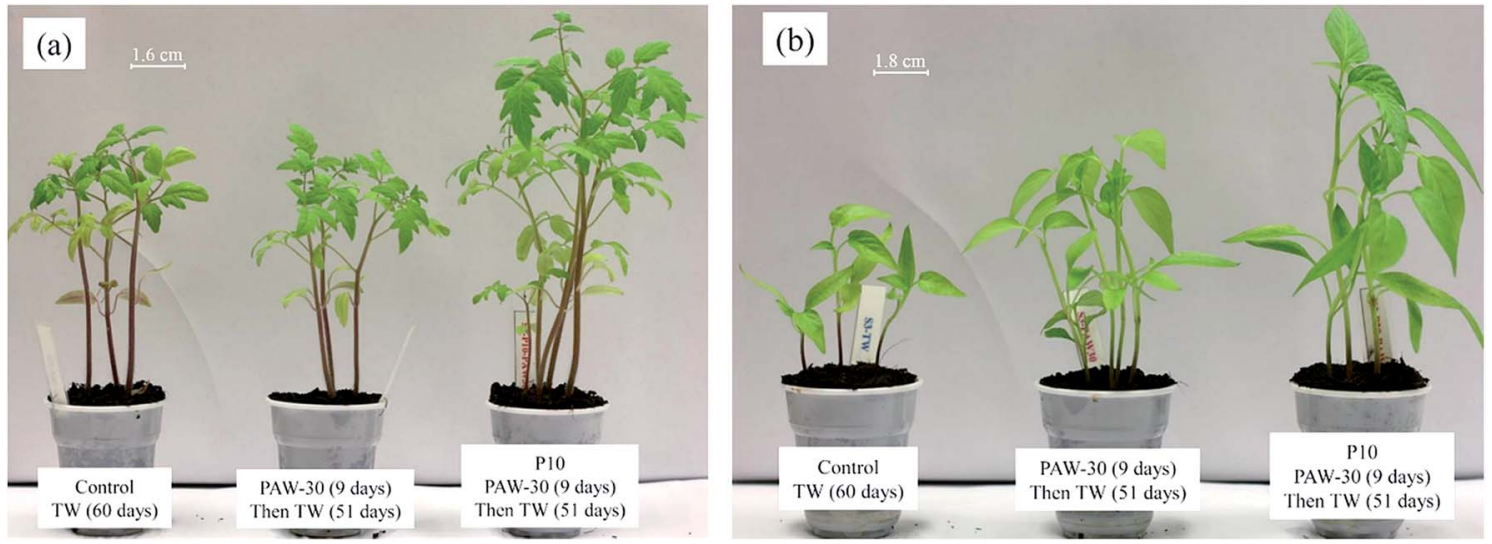

Fig. 10 Long term effect of PAW and plasma seed treatment on plant growth. Images of (a) tomato and (b) pepper plants on $60^{\text {th }}$ day after sowing. 
pepper plants growth. The most promising results were obtained for the 10 min plasma treated seeds watered with PAW30. Interestingly, for untreated tomato seeds, no significant difference in plant growth is observed when watered with TW and PAW-30 as shown Fig. 10(a), whereas, for untreated pepper seeds a significant growth is observed when watered with PAW30 as compared to TW as shown in Fig. 10(b). The positive effect between PAW and seed treatment is observed for both tomato and pepper plants growth (P10 - PAW-30), furthermore, the leaves seem to be healthier than the controlled sample. This result shows that the effect of PAW on plant growth is not similar for all seeds investigated in this study. Therefore, it can be proposed that the combined effect of plasma treatment of seeds and water on plant growth could probably depends on the nature of the seeds.

\section{Conclusion}

The combined effects of NTP activated water and seeds on the rate of germination and plants growth of radish, tomato, and pepper seeds have been investigated. The systematic study led us to make the following conclusions.

(1) It is evidenced that the cylindrical DBD reactor can be used to selectively produce $\mathrm{NO}_{3}{ }^{-}$species, which is mainly involved in cell metabolic process, into water at atmospheric pressure and room temperature.

(2) The acidic solution obtained by Cyl-DBD process could be used as a fertilizer. The PAW has increased the radish seeds germination rate by $80 \%$ and improved the seedling growth as compared to TW. Therefore, it can be suggested that the crop yield could be increased in short duration and with less water consumption.

(3) The seeds germination efficiency is related to the PAW treatment time, i.e. the amount of nitrate $\left(\mathrm{NO}_{3}{ }^{-}\right)$and hydrogen peroxide $\left(\mathrm{H}_{2} \mathrm{O}_{2}\right)$ produced in the water.

(4) It is demonstrated that the acidity of the water is not only controlled by the $\mathrm{HNO}_{3}$ produced by the reactive nitrogen species but it also depends on the reactive oxygen species and their products $\left(\mathrm{OH}, \mathrm{O}, \mathrm{O}_{3}, \mathrm{HO}_{2} \ldots\right)$ produced by the discharge.

(5) The positive effect is observed between plasma-treated dry seeds and the PAW, regarding the germination and seedling growth, for tomato and pepper seeds as compared to untreated seeds under the similar experimental conditions. However, the plasma discharges on the wet seeds have significantly modified the seed surface and shown negative effect on the seed germination process.

(6) It is observed that the seed and water plasma treatment time has to be optimized for each type of seed. In order to understand the active role of the plasma discharge on the seed surface activation, further studies will be focused on the optimization of the plasma input power, plasma treatment time, seeds surface analysis and the nature of the carrier gas.

\section{References}

1 J. I. L. Morison, N. R. Baker and P. M. Mullineaux, Philos. Trans. R. Soc., B, 2008, 363, 639-658.
2 P. L. E. Bodelier and H. J. Laanbroek, FEMS Microbiol. Ecol., 2004, 47, 265-277.

3 Z. Zhou, Y. Huang, S. Yang and W. Chen, Agric. Sci., 2001, 2, 23-27.

4 D. Dobrin, M. Magureanu, N. B. Mandache and M. D. Ionita, Innovative Food Sci. Emerging Technol., 2015, 29, 255-260.

5 P. Sookwong, S. Yodpitak, J. Doungkaew, J. Jurithayo, D. Boonyawan and S. Mahatheeranont, J. Food Nutr. Res., 2014, 2, 946-951.

6 J. Ehlbeck, U. Schnabel, M. Polak, J. Winter, T. Von Woedtke, R. Brandenburg and K. Weltmann, J. Phys. D: Appl. Phys., 2011, 44, 013002.

7 M. Laroussi, IEEE Trans. Plasma Sci., 2002, 30, 1409-1415.

8 L. Ragni, A. Berardinelli, L. Vannini, C. Montanari, F. Sirri, M. E. Guerzoni and A. Guarnieri, J. Food Eng., 2010, 100, 125-132.

9 M. Laroussi and F. Leipold, Int. J. Mass Spectrom., 2004, 233, 81-86.

10 M. Moisan, J. Barbeau and S. Moreau, Int. J. Pharm., 2001, 226, 1-21.

11 J. P. Leaver and E. H. Roberts, Outlook Agric., 1984, 13, 47-153. 12 A. G. Taylor, J. Prusinski, H. J. Hill and M. D. Dickson, HortTechnology, 1992, 2, 336-344.

13 Y. Bashan, Can. J. Microbiol., 1998, 44, 168-174.

14 J. Jiang, X. He, L. Li, J. Li, H. Shao, Q. Xu, R. Ye and Y. Dong, Plasma Sci. Technol., 2014, 16, 54-58.

15 B. Sera, P. Spatenka, M. Sery, N. Vrchotovs and I. Hruakova, IEEE Trans. Plasma Sci., 2010, 38, 2963-2968.

16 K. Koga, S. Thapanut, T. Amano, H. Seo, N. Itagaki, N. Hayashi and M. Shiratani, Appl. Phys. Express, 2016, 9, 016201.

17 D. P. Park, K. Davis, S. Gilani, C. A. Alonzo, D. Dobrynin, G. Friedman, A. Fridman, A. Rabinovich and G. Fridman, Curr. Appl. Phys., 2013, 13, S19-S29.

18 J. Takahata, K. Takaki, N. Satta, K. Takahashi, T. Fujio and Y. Sasaki, Jpn. J. Appl. Phys., 2015, 54, 01AG07.

19 J. C. Volin, F. S. Denes, R. A. Young and S. M. T. Park, Crop Sci., 2000, 40, 1706-1718.

20 N. Khamsen, D. Onwimol, N. Teerakawanich, S. Dechanupaprittha, W. Kanokbannakorn, K. Hongesombut and S. Srisonphan, ACS Appl. Mater. Interfaces, 2016, 8, 19268-19275.

21 P. Basaran and U. Akhan, Innovative Food Sci. Emerging Technol., 2010, 11, 113-117.

22 K. Oehmigen, M. Hahnel, R. Brandenburg, C. Wilke, K. D. Weltmann and T. von Woedtke, Plasma Processes Polym., 2010, 7, 250-257.

23 P. Bruggeman and C. Leys, J. Phys. D: Appl. Phys., 2009, 42, 053001.

24 C. A. Shoemakerl and W. H. Carlson, HortScience, 1990, 25, 762-764.

25 L. Sivachandiran and A. Khacef, $R S C A d v ., 2016$, 6, 2998329995.

26 L. Sivachandiran, F. Thevenet, P. Gravejat and A. Rousseau, Chem. Eng. J., 2013, 214, 17-26.

27 J. W. Lackmann, S. Schneider, E. Edengeiser, F. Jarzina, S. Brinckmann, E. Steinborn, M. Havenith, J. Benedikt and J. E. Bandow, J. R. Soc., Interface, 2013, 10, 591-602. 
28 B. Benstaali, D. Moussa, A. Addou and J. L. Brisset, Eur. Phys. J.: Appl. Phys., 1998, 4, 171-179.

29 P. Lukes, PhD Dissertation, Institute of Plasma Physics AS CR, Prague, Czech Republic, 2002.

30 J. L. Brisset, J. Lelievre, A. Doubla and J. Amouroux, Rev. Phys. Appl., 1990, 25, 535-543.

31 W. Dröge, Physiol. Rev., 2002, 82, 47-95.

32 E. Arc, M. Galland, B. Godin, G. Cueff and L. Rajjou, Front. Plant Sci., 2013, 4, 1-13.

33 G. Krouk, N. M. Crawford, G. M. Coruzzi and Y. F. Tsay, Curr. Opin. Plant Biol., 2010, 13, 266-273.

34 J. D. Bewley and M. Black, Seeds: Physiology of development and germination, Plenum Press New York, London, 2th edn, 1994, ISBN 0-306-44747-9.
35 K. Takaki, J. Takahata, S. Watanabe, N. Satta, O. Yamada, Y. Sasaki and T. Fujio, J. Phys.: Conf. Ser., 2013, 418, 012140.

36 I. Filatova, V. Azharonoki, V. Lushkevich, A. Zhukovsky, G. Gadzhieva and K. Spasic, 31st Int. Conf. Phenom. Ioniz. Gases (ICPIG), Granada, Spain, 2013.

37 I. Filatova, V. Azharonok, M. Kadyrov, V. Beljavsky, A. Gvozdov, A. Shik and A. Antonuk, Rom. J. Phys., 2011, 56, 139-143.

38 S. Kitazaki, K. Koga, M. Shiratani and N. Hayashi, Jpn. J. Appl. Phys., 2012, 51, 01AE01.

39 S. H. Ji, T. Kim, K. Panngom, Y. J. Hong, A. Pengkit, D. H. Park, M. H. Kang, S. H. Lee, J. S. Im, J. S. Kim, H. S. Uhm, E. H. Choi and G. Park, Plasma Processes Polym., 2015, 12, 1164-1173. 